\title{
Síndrome da criança hipotônica: causas neuromusculares
}

\author{
Floppy infant syndrome due to \\ neuromuscular disorders
}

\author{
Umbertina Conti Reed ${ }^{1}$
}

Reed UC. Síndrome da criança hipotônica: causas neuromusculares. Rev Med (São Paulo). 2007 abr.-jun.;86(2):82-93.

RESUMO: A síndrome da criança hipotônica engloba as condições em que a hipotonia muscular se manifesta no recém-nascido ou nos primeiros dois anos de vida. Inclui um grande número de situações que podem ser divididas em dois subtipos: a hipotonia intrínseca ou primária, que depende do acometimento das estruturas que compõem a unidade motora periférica desde o motoneurônio medular até o músculo, e a hipotonia secundária. Esta última ocorre principalmente como sinal acessório em afecções neurológicas com comprometimento do sistema nervoso central, ou no contexto de síndromes genéticas, bem como de doenças sistêmicas graves de caráter extraneurológico. Neste trabalho nos referiremos apenas às situações de hipotonia intrínseca, ou seja, doenças neuromusculares, caracterizando as principais afecções deste grupo no recém-nascido e no lactente, e enfatizando quais os aspectos clínicos que permitem orientar as hipóteses diagnósticas e indicar os exames complementares adequados, principalmente, os testes moleculares, quando possíveis.

DESCRITORES: Hipotonia muscular/congênito. Doenças neuromusculares/patologia. Polineuropatias/congênito. Miopatias congênitas estruturais. Distrofias musculares/congênito.

\section{INTRODUÇÃO}

A síndrome da criança hipotônica inclui um grande número de situações que podem ser de enfoque neurológico ou pediátrico. Sabendo-se que o tônus muscular depende da integridade do arco reflexo, sobre o qual atuam diversas influências suprasegmentares moduladoras, é fácil entender que existem dois grandes grupos de hipotonia muscular: a hipotonia intrínseca ou primária e a hipotonia secundária. A primeira depende do acometimento das estruturas

\footnotetext{
${ }^{1}$ Professora Titular do Departamento de Neurologia. Disciplina de Neurologia Infantil.

Endereço para correspondência: e-mail: ucontireedf@hcnet.usp.br
} 
que compõem o arco reflexo, ou seja, a unidade motora periférica desde o motoneurônio medular até o músculo, passando pelas raízes, nervos periféricos, junção mioneural e músculos. A hipotonia secundária ocorre principalmente no contexto clínico de afecções neurológicas com comprometimento supranuclear (sistema nervoso central-SNC), sendo também considerada hipotonia secundária a que se manifesta no contexto de síndromes genéticas (o exemplo típico é a síndrome de Down), de doenças sistêmicas graves de caráter extraneurológico (criança gravemente enferma), ou ainda nas situações que afetam tendões e ligamentos, principalmente nas doenças do colágeno. Finalmente, a hipotonia muscular é algumas vezes de caráter constitucional, freqüentemente familiar, conforme pode ser observado em pessoas extrememente hiperextensíveis e contorcionistas. Existe ainda a possibilidade de crianças pouco estimuladas ou hiperprotegidas, às vezes instucionalizadas, se apresentarem hipotônicas ao longo dos dois primeiros anos do desenvolvimento.

Apesar de as causas de hipotonia intrínseca ou primária, genericamente denominadas doenças neuromusculares, serem mais raras do que as de hipotonia secundária, constituem o principal enfoque da síndrome da criança hipotônica, já que são aquelas em que os componentes do arco reflexo, que mantém o tônus muscular, encontram-se primariamente afetados.

Assim, abordaremos aqui especificamente as doenças neuromusculares, que compõem o diagnóstico diferencial da síndrome da criança hipotônica com hipotonia intrínseca ou primária, sendo que as causas cerebrais serão referidas resumidamente para ilustrar o diagnóstico diferencial entre as duas formas de hipotonia muscular.

\section{QUADRO CLÍNICO E DIAGNÓSTICO}

Como distinguir as condições em que a hipotonia é intrínseca ou primária daquelas com hipotonia secundária a doenças sistêmicas ou a causas neurológicas supranucleares, isto é cerebrais ou centrais? O diagnóstico diferencial entre estas diferentes causas de hipotonia muscular no recémnascido (RN) e no lactente parte do reconhecimento da existência ou não de fraqueza muscular e paralisia acompanhando o quadro de hipotonia. A primeira distinção pode ser efetuada, examinando o bebê em posição supina e verificando se é capaz de mover ativamente os membros contra a gravidade, espontaneamente ou sob estimulação, e de manter a postura de um membro que tenha sido passivamente elevado. Dubowitz ${ }^{(6,7)}$, professor inglês universalmente conhecido no estudo da síndrome da criança hipotônica, estabeleceu duas grandes divisões de doenças que provocam hipotonia: o grupo paralítico, que engloba as doenças neuromusculares e o grupo não paralítico. Além desta diferença básica que nem sempre é facilmente determinada, observam-se outras diferenças que podem ser resumidas no Quadro 1.

Quadro 1. Grupo paralítico e não paralítico.

\begin{tabular}{|l|l|}
\hline GRUPO PARALÍTICO & GRUPO NÃO PARALÍTICO \\
\hline $\begin{array}{l}\text { Hipotonia generalizada, tanto axial como apendicular } \\
\text { Fraqueza muscular difusa ou de predomínio proximal em } \\
\text { cinturas, podendo acometer musculatura ocular } \\
\text { (ptose palpebral), facial (fácies alongado e dismórfico) } \\
\text { e bulbar }\end{array}$ & $\begin{array}{l}\text { Alerta precário com resposta pobre a estímulos auditivos e visuais } \\
\text { Sucça / deglutição não coordenadas }\end{array}$ \\
\hline $\begin{array}{l}\text { Atrofia muscular e, ocasionalmente, fasciculações } \\
\text { Hipo/arreflexia dos reflexos profundos }\end{array}$ & $\begin{array}{l}\text { Distúrbios metabólicos associados, sobretudo acidose metabólica } \\
\text { Crises epilépticas }\end{array}$ \\
\hline $\begin{array}{l}\text { Retrações fibrotendíneas, deformidades esqueléticas em } \\
\text { extremidades, quadril (luxação congênita) e coluna, } \\
\text { artrogripose, palato ogival }\end{array}$ & Hipotonia de predomínio axial \\
\hline
\end{tabular}

A artrogripose, que consiste em múltiplas deformidades articulares presentes ao nascimento, significa que ocorreu imobilidade intra-útero, a qual, ocasionalmente, é lembrada retrospectivamente pela mãe que relata diminuição dos movimentos fetais. Embora possa ocorrer também em doenças cerebrais e extraneurológicas, é mais comum nas doenças neuromusculares. Outro dado que traduz diminuição da motilidade intra-uterina, sendo referido principalmente nas miopatias congênitas, é a luxação da articulação coxofemural, já que a cavidade do acetábulo para se formar necessita das forças decorrentes da contração muscular intra-útero. Nos casos de doenças neuromusculares mais graves, também existe relato de polihidrâmnio, pela dificuldade do feto de deglutir o líquido amniótico.

Além destes dados semiológicos gerais, ao avaliar o RN ou o lactente hipotônico, a anamnese é 
de primordial importância para a distinção entre causas centrais e neuromusculares de hipotonia. Antecedentes de possíveis fatores pré ou perinatais adversos podem sugerir encefalopatia não progressiva, ao passo que antecedentes hereditários e familiares positivos levantam a suspeita de raras causas de acometimento cerebral progressivo, sendo particularmente importante o dado de que na família já ocorreu anteriormente óbito de $\mathrm{RN}$ ou lactente em condições de hipotonia e letargia, o que sugere provável encefalopatia metabólica (organo/acidopatia).

Por outro lado, antecedentes hereditários e/ou consangüinidade também são importantes nos casos de doenças neuromusculares, já que em $\mathrm{RN}$, lactentes e crianças pequenas as doenças neuromusculares hereditárias são muito mais freqüentes do que as adquiridas. O exame físico também deve ser valorizado, podendo revelar aspectos dismórficos que são peculiares em algumas doenças tanto neuromusculares (distrofia miotônica congênita, miopatia nemalínica, distrofia muscular congênita merosina-negativa e outras) como em muitas das cromossomopatias (Down, Prader-Willi e outras) e em algumas encefalopatias progressivas raras, por exemplo, doença de Zellweger.

Lesões malformativas em múltiplos órgaõs e/ ou sistemas, que geralmente indicam comprometimento do SNC e, portanto, hipotonia central podem ser evidenciadas pelo exame físico e/ou por exames complementares, permitindo estabelecer a suspeita diagnóstica com relativa facilidade e indicar o estudo genético para confirmação.

Suspeitando-se de hipotonia de causa central, muito mais comum do que aquela decorrente das doenças neuromusculares, os exames complementares importantes para uma triagem preliminar entre as principais etiologias progressivas e não progressivas são:

- Dosagem sérica de lactato / piruvato;

- Gasometria e amoniemia;

- Aminoácidos séricos e organoácidos urinários;

- Função tiroidiana e hepatica;

- Cariótipo (citogenética convencional), análise de metilação e provas de hibridização in situ (fluorescente ou não);

- Neuroimagem: tomografia e ressonância magnética.

Se estes exames preliminares originarem a suspeita de uma encefalopatia hereditária de natureza degenerativa ou metabólica, existem exames laboratoriais específicos, a nível bioquímico ou molecular, que podem confirmar ou afastar a hipótese diagnóstica. Da mesma forma, atualmente, quando a suspeita é de uma doença neuromuscular, os avanços da última década em genética molecular estão permitindo, conforme resumiremos adiante, que diversas afecções heredodegenerativas sejam diagnosticadas, inclusive no $\mathrm{RN}$, sem precisar recorrer a técnicas mais invasivas, tais como eletromiografia (EMG) ou biópsia muscular.

\section{ASPECTOS CLÍNICOS DA HIPOTONIA} INTRÍNSECA OU PRIMÁRIA E AS PRINCIPAIS DOENÇAS NEUROMUSCULARES NO RN E LACTENTE ${ }^{6,7,12,14-19}$

O RN ou lactente com hipotonia grave de causa neuromuscular apresenta características semiológicas peculiares (Figura 1): a suspensão ventral evidencia a ausência de sustento da cabeça e os membros pendentes em deflexão; a tração pelas mãos (manobra do arrasto) na posição supina também denota a falta de sustento da cabeça; nos membros inferiores, observa-se atitude em batráquio, com hiperabdução das coxas, e nos membros superiores, a manobra da "écharpe" denota acentuada falta de resistência à movimentação passiva, com os cotovelos cruzando-se além da linha média, sem que se formem ângulos articulares.
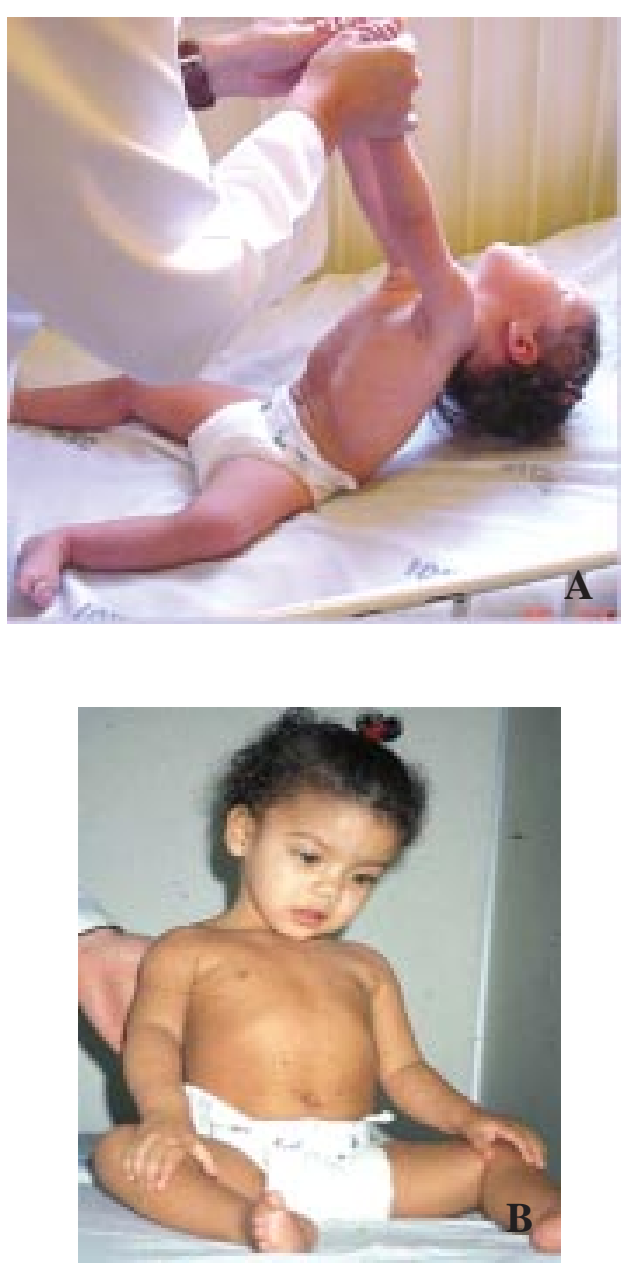

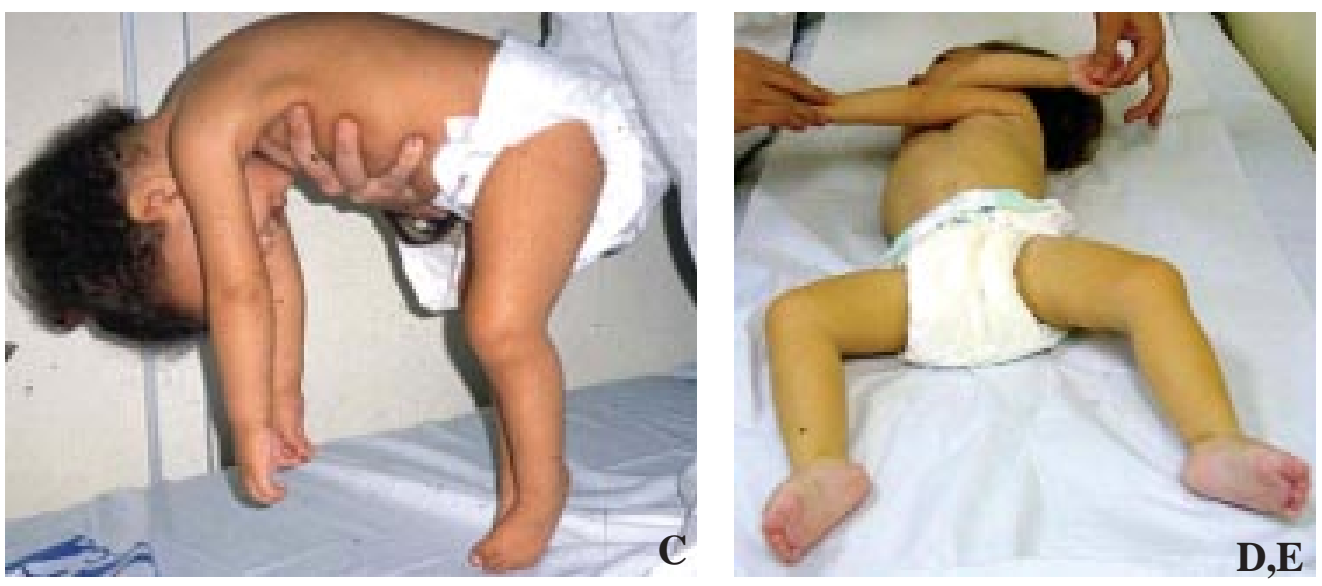

Figura 1. Aspectos semiológicos da hipotonia de causa neuromuscular em criança com um ano de idade. Em a e b, retardo acentuado do desenvolvimento motor: falta de sustento completo da cabeça (a); não senta sem apoio (b); em c, suspensão ventral com os membros pendentes em deflexão; em d, atitude em batráquio; em e, falta de resistência à movimentação passiva na manobra do cachecol.

A hipertonia em semiflexão própria do $\mathrm{RN}$ normal que contrasta com a hipotonia fisiológica própria do lactente normal, torna a síndrome da criança hipotônica mais evidente e facilmente diagnosticável no $\mathrm{RN}$ do que no primeiro ano de vida, durante o qual o dado semiológico mais importante é o retardo do desenvolvimento motor, causa comum de consulta a pediatras e neurologistas infantis. $O$ retardo do desenvolvimento neuropsicomotor (DNPM) global (motor, cognitivo, linguagem) associado à hipotonia muscular, sugere mais caracteristicamente uma causa central (cerebral), embora as doenças neuromusculares também possam, eventualmente, cursar com comprometimento associado do SNC.

As principais doenças neuromusculares que cursam com hipotonia no recém-nascido $(R N)$ ou no lactente são classificadas de acordo com a topografia da lesão dentro da unidade motora:

- Afecções do neurônio motor periférico (motoneurônio medular localizado no corno anterior ou ventral da medula espinal): amiotrofia espinal infantil tipos I, II e III (locus 5 q) 3 ,11,17,18,20; formas mais raras, não ligadas ao locus $5 q$;

- Polineuropatias hereditárias sensitivomotoras (PHSM) ${ }^{1,17,18}$ : formas hipomielinizante congênita, congênita grave e infantil da PHSM-III (Dejerine-Sottas); disautonomia familiar (Riley-Day);

- Junção mioneural: forma neonatal transitória de miastenia grave; síndrome miastênica congênita9;

- Miopatias:

- distrofia muscular congênita (DMC) $)^{13,15,17,18 \text { : }}$ formas merosina-negativa, hipotônico-esclerótica (Ullrich), espinha rígida, Fukuyama, músculo-óculo cerebral, Walker-Warburg e outros subtipos de DMC merosina-positiva;
- distrofia miotônica congênita ${ }^{16,17,18}$;

- forma infantil da distrofia fácio-escápuloumeral;

- miopatias congênitas estruturais ("central core", nemalínica, miotubular/centronuclear, com agregados de proteínas, etc.); não estruturais (desproporção congênita de fibras e outras); mistas (alterações mínimas e outras) $^{16}$;

- miopatias metabólicas $2,4,5,8,10,16-18$ : mitocondriopatias; distúrbios da beta-oxidação; glicogenoses.

A abordagem clínica, valorizando determinados sinais ou sintomas, é fundamental para indicar os métodos diagnósticos adequados a cada tipo de doença neuromuscular, sobretudo quando se suspeita de uma doença passível de diagnóstico molecular, o qual evita métodos invasivos. Os principais indicadores clínicos que orientam o diagnóstico diferencial e os exames confirmatórios são os seguintes: clínico

Idade de início e gravidade do quadro

Em crianças com hipotonia grave desde o nascimento, é freqüente o encontro de dificuldade alimentar e respiratória e não são superadas as etapas do DNPM, ou são superadas com muito atraso. O relato de movimentos fetais diminuídos pode ser espontâneo ou evocado na anamnese. Nestas condições as principais suspeitas diagnósticas, em ordem de freqüência, são:

- Amiotrofia espinal infantil (AEI) 3,11,17,18,20: nos dois primeiros anos de vida é a doença neuromuscular mais comum em crianças, 
apresentando incidência de aproximadamente 1:10000 e uma freqüência de portadores de 1:50. De herança autossômica recessiva, é causada por mutações no gene SMN (survival motor neuron) no locus 5q11-q13, e consiste de degeneração dos motoneurônios espinais e dos núcleos de alguns nervos cranianos. No tipo I ou doença de WerdnigHoffmann, o quadro de hipotonia e paralisia praticamente difusas é gravíssimo e se inicia intraútero, ao nascimento ou nos primeiros três meses de vida, evoluindo com insuficiência respiratória somente controlada através de ventilação mecânica e impedindo qualquer tipo de aquisição motora. As fasciculações são contrações involuntárias das fibras musculares de unidades motoras denervadas e podem ser verificadas espontaneamente ou provocadas pela percussão muscular, sobretudo na musculatura da língua e peitoral; não são constantes, mas quando ocorrem, têm valor patognonômico.

No segundo semestre de vida, quando a criança já permanece sentada, manifesta-se a forma intermediária da $\mathrm{AEI}$, ou $\mathrm{AEI}$ tipo II, que embora pareça inicialmente lentamente progressiva, passa a apresentar curso rapidamente evolutivo com grave atrofia, deformidades esqueléticas e insuficiência respiratória a partir da idade escolar. Neste tipo de $\mathrm{AEI}$ as fasciculações freqüentemente se acompanham de polimioclonias nas porções distais dos membros, visíveis na hiperextensão dos dedos. Finalmente, a partir do segundo ano de vida e durante toda a infância, quando a criança já adquiriu a marcha independente, manifesta-se a AEI tipo III ou forma juvenil, que apresenta quadro clínico amplamente variável quanto à gravidade, com diferentes graus de fraqueza muscular, atrofia, retrações fibrotendíneas e cifoescoliose, que pode ou não culminar em insuficiência respiratória na segunda década de vida. O diagnóstico molecular destas formas de AEI está na atualidade relativamente acessível nos grandes centros, sendo inclusive possível o diagnóstico prénatal.

Nos últimos três anos têm se conseguido excitantes progressos na direção de uma eventual terapia efetiva para esta gravíssima doença neuromuscular ${ }^{20}$.

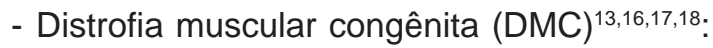
é um tipo de miopatia altamente heterogênea, tanto clinica quanto geneticamente, de herança autossômica recessiva e prevalência de 1:30000; caracteriza-se por hipotonia e fraqueza muscular de início ao nascimento ou no primeiro ano de vida e por tecido muscular de padrão distrófico, inespecífico. Existem inúmeros subtipos, classificados de acordo com o defeito molecular, porém as formas que se manifestam com gravidade desde o nascimento são fundamentalmente a DMC merosina-negativa, a DMC hipotônica-esclerótica (Ullrich) e as formas cérebroóculo-musculares (alfa-distroglicanopatias).

A forma merosina-negativa é a DMC mais freqüente no Brasil e decorre da mutação em 6q22 no gene da laminina á2 (merosina), proteína da matriz extracelular da fibra muscular que desempenha papel fundamental na estabilidade da membrana da célula muscular. O quadro clínico é grave desde o nascimento, com intensa hipotonia, sendo sentar-se a máxima habilidade motora alcançada; a progressão é lenta, porém inexorável, e ocorre dismorfismo facial típico, com fácies alongada e palato em ogiva. Devido ao fato de a merosina também influenciar o funcionamento da barreira hemato-encefálica, a neuroimagem mostra alteração difusa da substância branca cerebral, não ocorrendo, entretanto, manifestações de encefalopatia, já que todas as crianças desenvolvem inteligência normal ou, mais raramente, limítrofe.

DMC hipotônica-esclerótica (Ullrich): o quadro é geralmente grave desde o nascimento, mais raramente moderado e de início no lactente. Esta forma de DMC é causada por mutações que afetam os três genes responsáveis pela produção da unidade VI do colágeno (mutações de efeito recessivo nos genes COL6A 2 e 3 e mutação de efeito dominante no gene COL6A 1) que, ao lado da laminina á2 (merosina), é um componente essencial da matriz extracelular contribuindo para a estabilidade da membrana da fibra muscular. Nesta forma, a hipotonia e a fraqueza muscular são graves e, caracteristicamente, ocorre predomínio proximal das retrações, ou seja, em joelhos e cotovelos (geralmente as retrações predominam nas extremidades); há aspectos dismórficos faciais, calcanhar saliente, e o curso é progressivo, com insuficiência respiratória grave e cifoescoliose na adolescência.

Nas formas cérebro-óculo-musculares de DMC, as mutações ocorrem em diferentes genes que regulam o mecanismo bioquímico de glicosilação da proteína á-distroglicana ${ }^{13}$, que se localiza justaposta à membrana da fibra muscular, efetuando a ligação desta com a merosina da matriz extracelular. $\mathrm{Na}$ maioria das vezes, estes quadros são de início neonatal e costumam ser gravíssimos, associando quadro muscular, ocular e encefalopático, que evolui com deficiência mental, epilepsia, alterações visuais e oculares (retina ou câmara anterior) e retardo acentuado do DNPM. A neuroimagem mostra variados tipos de malformações corticais que podem chegar ao extremo da agiria (lissencefalia tipo II), que é conhecida como síndrome de Walker-Warburg, ou, 
ainda alterações cerebelares.

- Distrofia miotônica congênita (doença de Steinert) ${ }^{15-18}$ : a doença de Steinert, com herança autossômica dominante e exibindo o fenômeno da antecipação em gerações sucessivas, é a miopatia hereditária mais comum em adultos e está associada a comprometimento sistêmico amplamente variável. Em adultos caracteriza-se semiologicamente pela ocorrência do fenômeno miotônico, que consiste na ausência de relaxamento após a contração voluntária muscular, que pode ser verificada no aperto de mãos, percutindo a língua ou a eminência tênar, ou quando o paciente, ao espirrar, não consegue reabrir os olhos. As mulheres em idade fértil, principalmente quando apresentam o quadro multisistêmico, têm alto risco $(80 \%)$ de transmitir aos seus fetos a forma congênita que se caracteriza por polihidrâmnio, quadro neonatal grave com dificuldade alimentar e respiratória, artrogripose freqüente, principalmente com pés tortos e intenso acometimento oro-facial. Após um primeiro ano de vida conturbado, o quadro permanece estável durante a infância com atraso da fala e deficiência mental leve, estando o fenômeno miotônico ausente nos primeiros anos de vida. $\mathrm{Na}$ adolescência ocorre evolução variável para comprometimento multisistêmico, que pode até incluir estado demencial. A doença é passível de diagnóstico molecular, inclusive diagnóstico fetal. Pode acontecer que a mãe seja pouco acometida e desconheça o seu diagnóstico; portanto, frente a um quadro neonatal sugestivo, para orientar o teste molecular, é fundamental atestar se a mãe apresenta dismorfismo facial, fenômeno miotônico ou antecedentes familiares sugestivos de comprometimentos multisistêmicos (entre muitos, salienta-se catarata, cardiopatia, distúrbios endócrinos e calvície precoce).

- Miopatias metabólicas 2,4,5,8,10,15,17,18: são resultantes de falência da produção energética, por defeito primário do metabolismo das mitocôndrias, dos ácidos graxos ou do glicogênio. Estas categorias recebem a denominação de mitocondriopatias (doenças da fosforilação oxidativa), distúrbios da beta-oxidação e glicogenoses, respectivamente.

Entre as glicogenoses, a forma II, por deficiência da enzima lisossomal alfa-glucosidade ácida (doença de Pompe), apresenta um subtipo que pode estar evidente já ao nascimento ou precocemente, embora na maioria dos casos leve alguns meses para se manifestar; também a forma IV, por deficiência da enzima ramificadora (doença de Andersen), extremamente rara, pode causar intensa hipotonia nas primeiras semanas ou no lactente. Em ambas estas gravíssimas doenças, a herança é autossômica recessiva e o comprometimento é multisistêmico (muscular, cardíaco e visceral), sendo que, na doença de Pompe, existe também acometimento associado do SNC e do sistema nervoso periférico. Nos últimos anos, o diagnóstico precoce da doença de Pompe, por dosagem enzimática em cultura de fibroblastos ou através da biópsia muscular que evidencia o acúmulo de gliocogênio nas fibras musculares, é absolutamente essencial, devido ao relativo sucesso dos esquemas terapêuticos que empregam reposição enzimática.

As mitocondriopatias ou doenças da fosforilação oxidativa e os distúrbios da betaoxidação são doenças de fisiopatologia altamente complexa e enorme heterogeneidade clínica e genética, que não poderia ser resumida numa revisão deste tipo. Muito raramente exibem acometimento muscular puro, sendo freqüentemente multisistêmicas, com comprometimento do SNC, coração, fígado e, particularmente nas mitocondriopatias, da retina, rim, pâncreas e sistema endócrino. Entre as mitocondriopatias predominantemente miopáticas, são mais comuns os defeitos da cadeia respiratória de herança mendeliana, ao passo que as encefalomiopatias costumam ter herança materna tipo mitocondrial, que engloba múltiplos tipos de mutações do DNA mitocondrial, originando deficiências enzimáticas diferentes, muitas das quais ainda sem correlação precisa com o fenótipo. Tanto a mesma mutação pode originar fenótipos diferentes, como o mesmo fenótipo pode decorrer de mutações diferentes. O protótipo da doença mitocondrial predominantemente muscular que causa grave hipotonia ao nascimento é o defeito da cadeia respiratória do Complexo IV-citocromo $\mathrm{C}$ oxidase (COX). Compreende: a forma infantil fatal, predominantemente muscular, porém, associada também com comprometimento renal, miocardiopatia, hepatopatia, acidose láctica e insuficiência respiratória, que leva à morte no primeiro ano de vida; e a forma infantil benigna que é grave no primeiro ano de vida, exibindo, a seguir, uma melhora progressiva, que chega à normalidade em dois a três anos (provavelmente devido ao funcionamento de isoenzima fetal). Em ambas, a biópsia muscular mostra, através de técnicas histoquímicas, todas as fibras musculares COX-negativas, ou seja sem este tipo de atividade enzimática.

- Miopatias congênitas estruturais ${ }^{15-18}$ : em sua maioria são miopatias hereditárias com intensa heterogeneidade genética, de início ao nascimento ou nos primeiros anos de vida, curso benigno, não progressivo ou lentamente progressivo, variabilidade 
clínica acentuada, e histopatologia caracterizada pelo encontro de anormalidades estruturais específicas da fibra muscular, facilmente evidenciáveis através da biópsia muscular e que permitem a classificação de diversos subtipos. Dois subtipos podem ser particularmente graves ao nascimento: a forma nemalínica neonatal ou congênita grave e a forma miotubular ligada ao X. A maioria dos casos da forma nemalínica neonatal (congênita grave) é de herança autossômica recessiva e decorre de mutações no gene da nebulina (locus 2q). O dismorfismo facial e o comprometimento bulbar são evidentes desde o nascimento e as intercorrências respiratórias podem ser fatais.

Já a forma miotubular, de herança ligada ao sexo, locus Xq28, decorre de mutações nos genes das proteínas MTMX e MTMR1, que são implicadas no processo de miogênese; trata-se de um quadro muito grave e a sobrevida é excepcional(21).

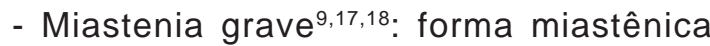
transitória e síndrome miastênica congênita

A forma miastênica transitória ocorre em 10 a $15 \%$ dos RN de mães miastênicas com a forma generalizada e com altos títulos de anticorpos antireceptor de ACh. Pode se notada ao nascimento, em algumas horas, ou raramente até o terceiro dia. $\mathrm{O}$ RN manifesta dificuldade para sugar e deglutir, porém a ptose palpebral é rara. Persiste de duas a quatro semanas, raramente de seis a oito, e constitui uma emergência neonatal pelo enorme risco de insuficiência respiratória. O diagnóstico é efetuado através do teste do Tensilon (brometo de edrofônio), por via IM ou subcutânea, e o tratamento com brometo de piridostigmina ou de neostigmina deve ser rapidamente instituído e mantido até a oitava semana.

Já a síndrome miastênica congênita compreende diferentes subtipos, de ocorrência esporádica ou de herança autossômica dominante, bem como recessiva, que se manifestam ao nascimento ou ao longo da infância e decorrem de mutações em diversos genes que codificam tanto alterações estruturais como funcionais da junção neuromuscular a nível pré-sináptico, sináptico ou póssináptico. O quadro clínico consiste na combinação variável de hipotonia muscular e sinais focais como ptose palpebral, choro fraco, comprometimento da musculatura cervical, facial e bulbar e as manifestações podem permanecer localizadas ou generalizar-se, chegando à insuficiência respiratória; em geral, não respondem aos anticolinesterásicos habituais.

\section{- Polineuropatias hereditárias sensitivo-}

motoras (PHSM) ${ }^{1,15,17,18}$ : trata-se de um grupo de doenças degenerativas dos nervos periféricos, de enorme heterogeneidade clínica e genética, e que podem ocorrer em qualquer idade. Dentro do diagnóstico diferencial da síndrome do bebê hipotônico, destacam-se a forma hipomielínica congênita, a forma congênita grave do tipo III (Dejerine-Sottas) e a síndrome de Riley-Day.

A PHSM tipo III (Dejerine-Sottas) é a mais freqüente em crianças e depende de diferentes tipos de mutações que afetam o metabolismo da mielina dos nervos periféricos: gene PMP 22 (17p11.2-12, proteína 22 da mielina periférica), P0 (1q22-q23, proteína zero da mielina) ou EGR2 (10q21-q22, gene da resposta ao crescimento precoce). A herança pode ser autossômica dominante ou recessiva e o quadro clínico é mais ou menos grave, desde hipotonia difusa com comprometimento respiratório e alimentar e mielina praticamente ausente nos nervos periféricos, que corresponde à forma hipomielínica congênita, até quadro pouco mais brando, porém sempre de início ao nascimento ou nos dois primeiros anos de vida, que evolui com retardo do desenvolvimento motor, possível hipertrofia de nervos periféricos, alterações distais de sensibilidade, hiperproteinorraquia e velocidade de condução motora muito reduzida, da ordem de $10 \mathrm{~m} / \mathrm{s}$ ou menos.

A disautonomia familiar ou síndrome de Riley-Day, muito rara, pode ser esporádica ou de herança autossômica recessiva em determinadas etnias judaicas. Além da hipotonia muito intensa ao nascimento, existe uma dificuldade característica para coordenar sucção e deglutição, instabilidade vasomotora, térmica e pressórica, ausência de papilas linguais e de lacrimação. Ocorre comprometimento cerebral, das raízes dorsais e dos nervos periféricos e o diagnóstico pode ser estabelecido através de reações anormais à instilação de pilocarpina na conjuntiva ou à injeção intradérmica de histamina. Os sintomas podem ser controlados através do emprego de derivados colinérgicos.

- Forma infantil da distrofia fácio-escápuloumeral ${ }^{15,17,18}$ : muito rara, pode ser esporádica ou de herança autossômica dominante com mutação no locus 4q35; é gravíssima, manifestando-se ao nascimento com plegia total e estando, ocasionalmente, associada com alterações vasculares retinianas, surdez neurosensorial, deficiência mental e epilepsia. Tanto nas crianças com esta forma muito rara, que pode ser esporádica, quanto nas famílias com a forma típica, que na maior parte das vezes inicia-se no final da primeira década ou na adolescência, o teste molecular pode permitir o diagnóstico. 
Nos casos com comprometimento motor moderado, embora o quadro se manifeste desde o nascimento, começa a ser reconhecido no lactente através de atraso variável do desenvolvimento motor, sobretudo quanto à aquisição de sentar sem apoio $\mathrm{e}$ da marcha sem apoio. O aspecto semiológico predominante é a falta de resistência à movimentação passive (Figura 2) e ao balanço passivo, além de hipotonia à palpação muscular. Diferentes graus de fraqueza muscular e de atrofia muscular, geralmente de predomínio proximal em cinturas, retrações fibrotendíneas e deformidades de coluna surgem ao longo da infância e adolescência, mas em geral a criança mantém marcha independente e apresenta graus moderados de incapacidade motora. Podem ser considerados exemplos de acometimento moderado:

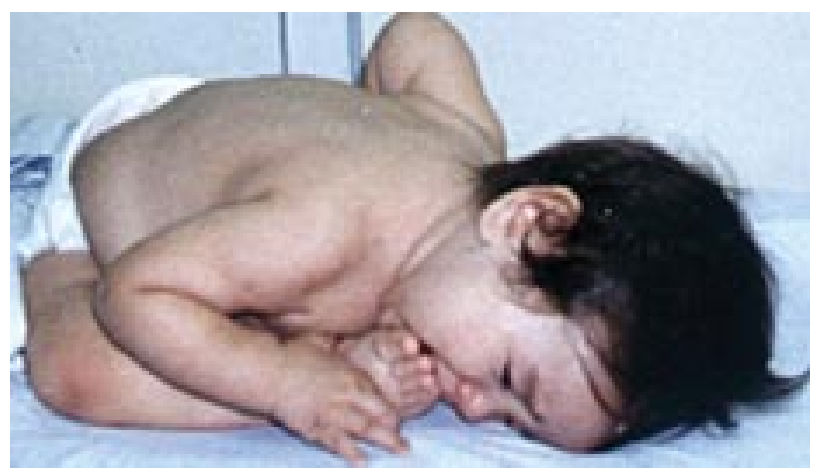

Figura 2. Aspectos sugestivos da hipotonia de causa neuromuscular: hiperextensibilidade articular.

- uma parte dos casos de AEI tipo III que, embora desenvolvam a marcha independente, apresentam precocemente atrofia muscular, retrações fibrotendíneas e cifoescoliose;

- a maior parte dos casos de DMC muscular pura com merosina normal, com ou sem defeito molecular identificado, particularmente a forma denominada espinha rígida, causada por alterações no gene da selenoproteína $\mathbf{N}$, implicada em processos de óxido-redução (locus 1p35-36). Embora na maioria das crianças o quadro clínico mostre cifoescoliose precoce, porém progressão acentuada somente a partir da adolescência, existem alguns casos graves desde o nascimento;

- uma parte das miopatias congênitas com anormalidades estruturais: forma congênita da miopatia miotubular/centronuclear não ligada ao X; forma congênita intermediária e forma típica da miopatia nemalínica; miopatias com agregados de proteínas; uma parte das miopatias congênitas sem anormalidades estruturais, principalmente do tipo desproporção congênita de fibras, que é diagnosticada através de técnicas histoquímicas aplicadas à biópsia muscular;
- mitocondriopatias com acometimento muscular puro;

- raros casos de PHSM tipo III (forma infantil de Dejerine-Sottas).

Quando o acometimento é leve permitindo que a criança, embora mostrando atrofia muscular, leve vida praticamente normal com poucas limitações, as principais hipóteses diagnósticas são:

- alguns casos de AEI tipo III, na primeira década da vida;

- miopatias congênitas com anormalidades estruturais do tipo "central core/minicore"; miotubular/ centronuclear não ligad ao X; forma leve infantil ou juvenil da miopatia nemalínica; miopatias congênitas não estruturais como a desproporção congênita de fibras e a miopatia congênita com alterações mínimas;

- mitocondriopatias com acometimento muscular puro e alguns distúrbios da beta-oxidação; de Pompe;

- a maioria das glicogenoses, exceto a doença congênitas.

Conforme já comentamos, o dismorfismo facial, com palato em ogiva e boca em formato de "carpa", o comprometimento da musculatura facial e ocular, sobretudo ptose palpebral, e a rara ocorrência de artrogripose multiplex congênita, evidenciada já ao nascimento, são manifestações altamente sugestivas de doença neuromuscular e constituem dados semiológicos importantes não só para o diagnóstico diferencial entre a hipotonia de causa central e periférica, bem como entre as diversas doenças neuromusculares possíveis (Figuras $3 \mathrm{a}, \mathrm{b}, \mathrm{c}$ ).

Acometimento facial é característico da:

- DMC merosina-negativa;

- distrofia miotônica congênita;

- miopatias congênitas nemalínica, miotubular e, mais raramente, desproporção congênita de fibras;

- miastenia grave neonatal transitória;

- síndrome miastênica congênita grave;

- forma infantil da distrofia fácio-escápuloumeral.

Ptose palpebral ou, mais rarmente acometimento de outros músculos extrínsecos oculares, sugere:

- síndrome miastênica congênita;

- mitocondriopatias, particularmente as de herança materna, por defeitos do DNA mitocondrial; - miopatia congênita miotubular/centronuclear; - desproporção congênita de fibras; - distrofia miotônica congênita. 

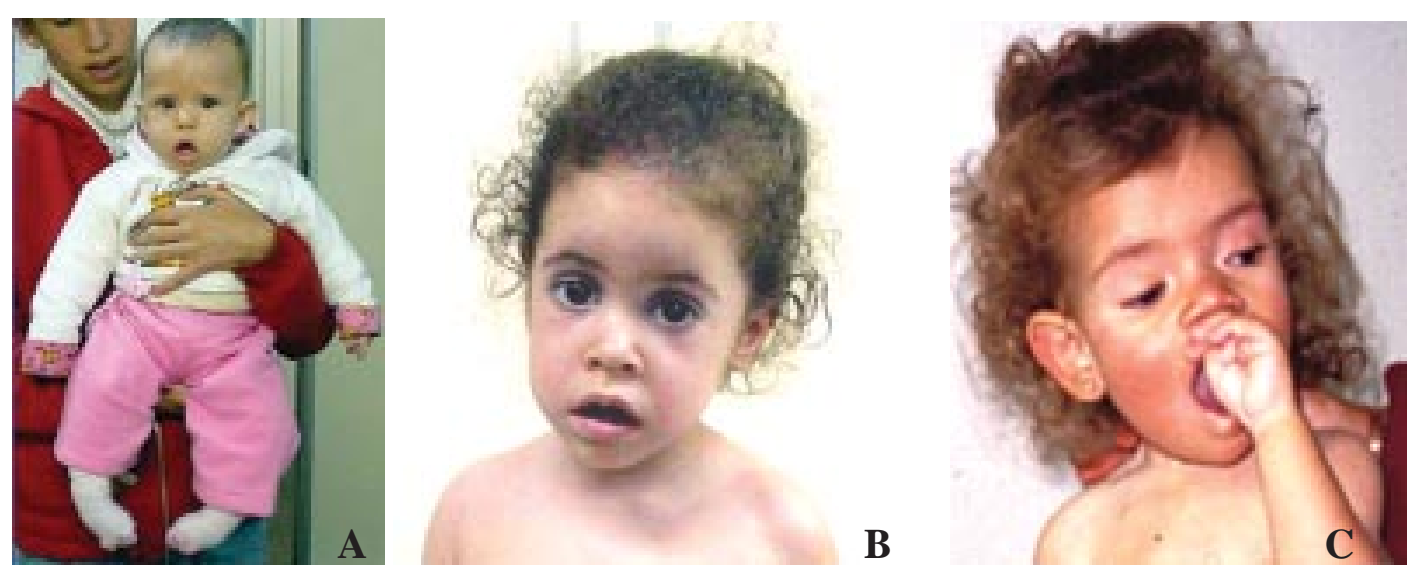

Figura 3. Aspectos sugestivos da hipotonia de causa neuromuscular: dismorfismo facial, boca em carpa e pés tortos congênitos (a); comprometimento facial (b); ptose palpebral (c).

Quadro de artrogripose multiplex congênita é mais encontrado em:

- distrofia miotônica congenital;

- polineuropatia do tipo hipomielínica congênita, bem como forma congênita e infantil do tipo III (Dejerine-Sottas);

- AEI tipo I;

- algumas formas de DMC, geralmente com merosina presente.

Outras características do quadro clínico devem ser levadas em conta, tais como:

- Curso flutuante e piora da fraqueza no decorrer do dia ou após um período de maior atividade sugere fenômeno miastênico, característico das afecções da junção mioneural;

- Evolução em surtos, desencadeados por infecções, atividade física, tipo de alimentação, "stress" e medicamentos, sugere diferentes tipos de miopatias metabólicas, tais como: mitocondriopatias, distúrbios da beta-oxidação e glicogenoses. Em casos particulares o surto pode culminar em mioglobinúria;

- Fadiga fácil, falta de resistência às atividades da vida diária, dores musculares e, eventualmente, cãibras também são mais comuns nas miopatias metabólicas;

- Hipertermia maligna: é uma manifestação gravíssima que pode ocorrer em diferentes miopatias, sendo caracteristicamente ligada à miopatia congênita estrutural do tipo central core, causada por mutações no locus 19q 13.1, no gene que codifica a proteína do receptor da rianodina, o mesmo que determina a suscetibilidade à hipertermia maligna. A miopatia tipo central core é na maioria das vezes relativamente benigna, causando hipotonia discreta e pouca fraqueza muscular de predomínio proximal; entretanto, quando há suspeita desta miopatia, devese sempre obter o diagnóstico de certeza através da biópsia muscular, a fim de evitar induções anestésicas inadequadas que possam desencadear a hipertermia maligna. Esta gravíssima intercorrência ocorre com a indução anestésica com halotano e succinilcolina, sendo causada por alteração do metabolismo do cálcio intracelular; é freqüentemente fatal, se não se dispuser de imediato de dantrolene sódico na sala cirúrgica;

- Associação com alterações sistêmicas, sobretudo hepaticas, cardíacas e endocrinológicas, metabólicas, principalmente acidose láctica, e com manifestações clínicas ou neurorradiológicas sugestivas de comprometimento do SNC: na avaliação da criança hipotônica é preciso estar atento à possibilidade de tais associações que, conforme já mencionamos sugerem fortemente diferentes tipos de miopatias metabólicas (distúrbios da betaoxidação, glicogenoses, mitocondriopatias), sendo que o acometimento do SNC pode também ser observado em alguns subtipos de DMC (distúrbios de glicosilação da á-distroglicana: formas músculoóculo-cerebrais), e na distrofia miotônica congênita (doença de Steinert), a qual, também pode estar associada, mais tardiamente, a um amplo espectro de alterações sistêmicas;

- Curso clínico altamente variável quanto ao espectro de gravidade, inclusive dentro da mesma família. Na maioria das afecções que citamos de forma resumida é possível uma ampla variabilidade fenotípica inter ou intra-familial. Exemplos de doenças neuromusculares com fenótipo altamente variável são:

- AEI tipo III;

- síndrome miastênica congenital; 
- DMC merosina-positiva com seus variados subtipos definidos por testes moleculares;

- algumas miopatias congênitas: nemalínica, miotubular/centronuclear, desproporção congênita de fibras;

- a maioria das mitocondriopatias e distúrbios da beta-oxidação.

PRINCIPAIS MÉTODOS DIAGNÓSTICOS QUE AUXILIAM NO DIAGNÓSTICO DIFERENCIAL ENTRE AS CAUSAS NEUROMUSCULARES DE HIPOTONIA

No campo neuromuscular, os últimos avanços moleculares ${ }^{1,3,12,13,14,15,17,18,20}$ permitem que diversas afecções heredodegenerativas sejam diagnosticadas através de testes moleculares, inclusive no $R N$, evitando técnicas mais invasivas, tais como eletromiografia (EMG) ou biópsia muscular:

- na AEI (deleção dos exons 7 e 8 do gene SMN no locus 5q11-q13);

- em algumas PHSM (genes da proteína PO e PMP22 da mielina periférica);

- na distrofia miotônica congênita (expansão da repetição do trinucleotídeo CTG em 19q13.3);

- na forma infantil da distrofia fácio-escápuloumeral (deleção de repetições de $3.3 \mathrm{~kb}$ em 4q35)

- em algumas encefalomiopatias mitocondriais (pontos específicos de mutação do DNA mitocondrial).

Entretanto, frente a uma criança hipotônica na qual se suspeita de doença neuromuscular, nem sempre é possível recorrer aos testes moleculares que não estão disponíveis para todas as doenças e nem sempre são acessíveis. Nestes casos, a avaliação clássica de uma doença neuromuscular inclui: determinação do nível sérico de creatinofosfoquinase (CPK), EMG e biópsia muscular.

O aumento de CPK diferencia o comprometimento muscular do neurogênico, embora aumentos muito discretos ocorram ocasionalmente na AEI. No RN, um aumento importante de CPK é sugestivo de:

- diferentes formas de DMC, puramente musculares (particularmente na forma merosinanegativa) ou associadas a comprometimento do SNC e ocular;

- mais raramente, observa-se aumento de CPK na distrofia miotônica congênita, nas miopatias mitocondriais e na miopatia congênita com desproporção de fibras;

- nas crianças maiores, além das doenças supracitadas em seu curso evolutivo, grandes aumento de CPK são particularmente encontrados nas distrofias musculares progressivas, principalmente nas formas ligadas ao sexo de Duchenne e Becker ${ }^{16}$, sendo que a primeira é a doença neuromuscular mais encontrada em crianças a partir dos três anos de idade e não faz parte do diagnóstico diferencial da síndrome do bebê hipotônico, já que se manifesta mais tardiamente. Entretanto, o menino com Duchenne que está em estágio pré-clínico, ainda sem sintomas evidentes, apresenta desde o nascimento altíssimos níveis de CPK, que podem confirmar o diagnóstico em um segundo filho nas famílias que já têm um menino afetado.

Aumentos expressivos de CPK também são verificados nas miopatias adquiridas de caráter autoimune (poli/dermatomiosites), de início agudo ou subagudo, que também não ocorrem em RN e lactentes e não se incluem dentro do diagnóstico diferencial da síndrome do bebê hipotônico.

A EMG permite distinguir entre o acometimento do neurônio motor, das raízes e nervos periféricos, da junção mioneural ou da fibra muscular: é indispensável para o diagnóstico imediato de AEI, quando o teste molecular for excessivamente demorado ou inacessível, bem como para os raros casos de PHSM (diminuição da velocidade de condução) e de síndrome miastênica congênita (decremento do potencial de ação). Em caso de miopatia com CPK elevado, a EMG pode ser dispensada; porém, é útil nas crianças já deambulantes com padrão proximal de fraqueza, a fim de diferenciar entre uma miopatia e a forma denominada pseudomiopática de AEI-III, que simula o quadro das distrofias musculares com fraqueza e atrofia de predomínio proximal, hiperlordose lombar, sinal do levantar miopático e, ocasionalmente, até hipertrofia de panturrilhas.

A biópsia muscular com microscopia óptica, complementada pela microscopia eletrônica, é importante para o diagnóstico das diferentes formas de miopatias congênitas com anormalidades estruturais, bem como das glicogenoses. Boa parte das mitocondriopatias não mostra achados específicos à biópsia muscular, exceto aquelas dependentes de mutações do DNA mitocondrial, que mostram na microscopia óptica (coloração Gomori modificado) as peculiares "ragged red fibers" e na microscopia eletrônica, proliferação anormal e alteração morfológica das mitocôndrias, bem como em algumas mitocondriopatias por defeitos do transporte do substrato (ciclo da carnitina) e da 
utilização do substrato (b-oxidação dos ácidos graxos) que podem apresentar acúmulo de lípides. Em algumas mitocondriopatias com deficiência dos complexos da cadeia respiratória, é possível analisar o defeito bioquímico enzimático por técnicas histoquímicas na biópsia muscular.

Nas crianças com DMC a biópsia muscular mostra aspectos distróficos inespecíficos, que se caracterizam por variabilidade desordenada do tamanho das fibras, aumento do tecido conetivo endo e perimisial e deposição de gordura, em maior ou menor grau; portanto, a análise imunohistoquímica utilizando anticorpos específicos, é fundamental para complementar a microscopia ótica, a fim de avaliar possíveis déficits de proteínas, tais como a merosina, o colágeno VI e a a-distroglicana que, quando presentes confirmam alguns dos diferentes subtipos de DMC.

Nas miopatias com comprometimento associado do SNC, a ressonância nuclear magnética do crânio pode mostrar alterações sugestivas destas entidades: nos núcleos da base e tronco cerebral em algumas mitocondriopatias; na substância branca, bem como malformações corticais e atrofia cerebelar em alguns dos subtipos de DMC já discutidos; e áreas inespecíficas de hipersinal em T2 na distrofia miotônica congênita.

Quando há suspeita de miopatia metabólica, particularmente mitocondriopatias (defeitos do metabolismo do piruvato, do ciclo de Krebs ou da cadeia respiratória), com ou sem acidose láctica, devem ser solicitados outros exames laboratoriais que constituem o perfil metabólico: lactato, piruvato, alanina e corpos cetônicos no sangue, LCR e urina, bem como eletrólitos, gasometria e perfil de acilcarnitina (b-oxidação dos ácidos graxos).

O diagnóstico diferencial das doenças musculares inclui ainda a avaliação cardiológica, visto que algumas mitocondriopatias, glicogenoses, miopatias congênitas e a distrofia miotônica podem apresentar miocardiopatia associada.

Reed UC. Floppy infant syndrome due to neuromuscular disorders. Rev Med (São Paulo). 2007 abr.-jun.;86(2):82-93.

\begin{abstract}
The congenital hypotonia, also known as the floppy infant syndrome, refers to an infant with generalized hypotonia presenting at birth or in early life. The most important aspect to be considered for assessing the diagnosis is to differentiate between a primary cause of hyptonia due to a neuromuscular disorder and a secondary cause due to non neurological conditions, chromosomal abnormalities or central nervous system involvement (cerebral causes of congenital hypotonia). The focus of the present review are: to report the main neuromuscular disorders, i.e. primary congenital hypotonia, that begin along the first two years of life; to describe the clinical aspects that suggest the differential diagnosis among these entities in order to allow a correct investigation and to avoid unnecessary methods of evaluation. It is also emphasized the value of the molecular diagnosis that is now available for some of these conditions.
\end{abstract}

KEY WORDS: Muscle hypotonia/congenital. Neuromuscular diseases/pathology. Polyneuropathies/congenital. Myopathies, structural, congenital. Muscular dystrophies/ congenital.

\title{
REFERÊNCIAS
}

1. Bennett CL, Chance PF. Molecular pathogenesis of hereditary motor, sensory and autonomic neuropathies. Curr Opin Neurol. 2001;14:621-7.

2. Borchert A, Wolf NI, Wilichowski E. Current concepts of mitochondrial disorders in childhood. Semin Pediatr Neurol. 2002;9:151-9.

3. Brahe C. Copies of the survival motor neuron gene in spinal muscular atrophy: the more, the better. Neuromuscul Disord. 2000;10:274-5.

4. Darras BT, Friedman NR. Metabolic myopathies: a clinical approach; part I. Pediatr Neurol. 2000;22:87-97.

5. Darras BT, Friedman NR. Metabolic myopathies: a clinical approach; part II. Pediatr Neurol. 2000;22:171-81.
6. Dubowitz V. Muscle disorders in childhood. 2nd ed. London: W B Saunders; 1995.

7. Dubowitz V. The floppy infant. London: William Heinemann Medical Book;1980. (Clinics in Developmental Medicine, 76).

8. Echenne B, Rivier F, Bellet H, Humbertclaude V, Roubertie A. Mitochondrial myopathies: their clinical, biological, morphological and molecular aspects. Arch Pediatr. 2002;9(Suppl 2):179-182.

9. Engel AG, Ohno K. Congenital myasthenic syndromes. Adv Neurol. 2002;88:203-15.

10. Gillis L, Kaye E. Diagnosis and management of mitochondrial diseases. Pediatr Clin North Am. 
2002;49:203-19.

11. lannaccone ST, Burghes A. Spinal muscular atrophies. Adv Neurol. 2002;88:83-98.

12. Johnston HM. The floppy weak infant revisited. Brain Dev. 2003;25:155-8.

13. Muntoni $F$, Voit $T$. The congenital muscular dystrophies in 2004: a century of exciting progress. Neuromuscul Disord. 2004;14:635-49.

14. Paro-Panjan D, Neubauer D. Congenital hypotonia: is there an algorithm? J Child Neurol. 2004;19:439-42.

15. Prasad AN, Prasad C. The floppy infant: contribution of genetic and metabolic disorders. Brain Dev. 2003;25:457-76.

16. Reed UC. Miopatias. In: Diament A, Cypel, S. Neurologia infantil. 4a ed. São Paulo: Atheneu; 2005. p.1385-430.
17. Reed UC. Síndrome da criança hipotônica. In: Fonseca LF, Pianetti G, Xavier CC. Compêndio de neurologia infantil. Rio de Janeiro: MEDSI; 2001. p 521-34.

18. Reed UC. Síndrome da criança hipotônica. In: Diament A, Cypel S. Neurologia infantil. 4a ed. São Paulo: Atheneu; 2005. p.1431-62.

19. Richer LP, Shevell MI, Miller SP. Diagnostic profile of neonatal hypotonia: an 11-year study. Pediatr Neurol. 2001;25:32-7.

20. Sumner CJ. Therapeutics development for spinal muscular atrophy. NeuroRx. 2006;3:235-45.

21. Zanoteli E, Laporte J, Rocha JC, Kretz C, Oliveira AS, Mandel JL, et al. Deletion of both MTM1 and MTMR1 genes in a boy with myotubular myopathy. Am J Med Genet. 2005;134:338-40. 